\title{
Zebrafish Embryonic Exposure to BPAP and Its Relatively Weak Thyroid Hormone-Disrupting Effects
}

\author{
Sangwoo Lee ${ }^{1}$, Kojo Eghan ${ }^{1,2}{ }^{\circledR}$, Jieon Lee ${ }^{1}$, Donggon Yoo ${ }^{1,2}{ }^{\circledR}$, Seokjoo Yoon ${ }^{2,3}$ \\ and Woo-Keun Kim ${ }^{1,2, *}$ \\ 1 Biosystem Research Group, Korea Institute of Toxicology, Daejeon 34114, Korea; \\ sangwoo.lee@kitox.re.kr (S.L.); keghan@kitox.re.kr (K.E.); jieon.lee@kitox.re.kr (J.L.); \\ donggon.yoo@kitox.re.kr (D.Y.) \\ 2 Human and Environmental Toxicology, University of Science and Technology, Daejeon 34113, Korea; \\ sjyoon@kitox.re.kr \\ 3 Department of Predictive Toxicology, Korea Institute of Toxicology, Daejeon 34114, Korea \\ * Correspondence: wookkim@kitox.re.kr; Tel.: +82-42-610-8305
}

Received: 13 October 2020; Accepted: 10 November 2020; Published: 13 November 2020

check for updates

\begin{abstract}
Safe endocrine-disrupting alternatives for bisphenol A (BPA) are needed because its adverse health effects have become a public concern. Some bisphenol analogues (bisphenol $\mathrm{F}$ and $\mathrm{S}$ ) have been applied, but their endocrine-disrupting potential is either not negligible or weaker than that of BPA. However, the endocrine-disrupting potential of bisphenol AP (BPAP), another BPA alternative, has not yet been fully assessed. Hence, we evaluated the thyroid hormone (TH)-disrupting potency of BPAP because THs are essential endocrine hormones. Zebrafish embryos were exposed to $\operatorname{BPAP}(0,18.2,43.4$, or $105.9 \mu \mathrm{g} / \mathrm{L}$ ) for $120 \mathrm{~h}$, and TH levels, the transcription of $16 \mathrm{TH}$-related genes, the transcriptome, development, and behavior were evaluated. In our study, a decrease in T4 level was observed only at the maximum nonlethal concentration, but significant changes in the T3 and TSH $\beta$ levels were not detected. BPAP did not cause significant changes in transcription and gene ontology enrichment related to the TH system. Developmental and behavioral changes were not observed. Despite T4 level reduction, other markers were not significantly affected by BPAP. These might indicate that BPAP has weak or negligible potency regarding TH disruption as a BPA alternative. This study might provide novel information on the TH-disrupting potential of BPAP.
\end{abstract}

Keywords: alternative chemical; BPA; endocrine disruption; thyroid hormone; zebrafish

\section{Introduction}

The endocrine-disrupting effects of bisphenol A (BPA) and its major alternatives, such as bisphenol $\mathrm{F}$ (BPF) and bisphenol S (BPS), have recently been reported [1-3]. As one of the integral endocrine systems, the thyroid hormone (TH)-disrupting effects of those chemicals need to be evaluated because THs play essential roles in many physiological processes, such as development, growth, reproduction, and metabolism [3,4]. BPA and other bisphenols, such as bisphenol AF (BPAF), BPF, and BPS, caused the disruption of the TH regulation system [1-5]. In our previous study, BPA, BPF, and BPS increased the level of T3 or T4 and changed related gene transcriptions in the zebrafish embryo/larvae model [3]. BPA, BPF, and BPS also induced the proliferation of TH-dependent rat pituitary cells (GH3) and biphasic responses of gene transcription in Pelophylax nigromaculatus tadpoles [2]. However, T4 level reduction was also shown by BPF and BPS $[1,4,5]$. Despite conflicting results for bisphenols regarding THs, the TH-disrupting effects of those bisphenols are evident. To find alternative chemicals that are relatively safer than BPA with respect to TH disruption, various candidates need to be evaluated. 
As an alternative candidate, bisphenol AP (BPAP), which is also known as 4,4'-(1-phenylethylidene) bisphenol, is used in polymer materials, the fine chemical industry, and the medicine industry. As an indispensable plasticizer and flame retardant, BPAP is used in the synthesis of plastic, rubber, and other industrial products [6]. The widespread use of these synthetic products has led to BPAP contamination of environments and foods, and therefore, the exposure of humans to this chemical [7]. BPAP was recently detected in various samples of personal care products and foods in China and the United States [8,9]. In a previous study, BPAP was detected in $10 \%$ of 231 personal care products, and based on the detection rate, BPAP was ranked third among eight bisphenols, following BPA and BPS [8]. In 289 food samples, BPAP was ranked third among bisphenols based on its mean concentration, following $\mathrm{BPA}$ and BPF, and the mean concentration of BPAP was relatively high in eggs and dairy products [9]. BPAP was found in human urine samples from Saudi Arabia at a range of 0.063 to $12.6 \mathrm{ng} / \mathrm{mL}$ [10] and from China at a range of $<\mathrm{LOQ}$ to $2.05 \mathrm{ng} / \mathrm{mL}$ [11,12]. In addition, BPAP was detected at up to $56 \mathrm{ng} / \mathrm{L}$ and $1.2 \mathrm{ng} / \mathrm{g} \mathrm{dw}$ in surface water from Luomo lake and sediment samples from Taihu lake, respectively [13]. In Korean domestic wastewater treatment plants, the measured concentration of BPAP was up to $16.0 \mathrm{ng} / \mathrm{g}$ dw [14]. However, the environmental levels and detection frequencies of BPAP were not higher than BPA and major alternatives of BPA, such as BPF and BPS $[13,14]$.

The toxicological information on BPAP remains insufficient. Regarding its TH-disrupting effects, only two in vitro studies have been performed $[15,16]$, and the effects are unclear. These previous studies revealed that BPAP at levels up to the maximum non-cytotoxic dose did not affect gene transcription in rat thyroid follicular cells (FRTL-5) [15], and the proliferation of GH3 cells was not changed under the T3 cotreatment conditions [16]. In contrast, under conditions without T3, treatment with the maximum non-cytotoxic dose of BPAP increased GH3 cell proliferation and decreased gene transcription $(\operatorname{tr} \alpha, \operatorname{tr} \beta$, and dio 2$)[15,16]$.

Because the TH-disrupting effects of BPAP remain unclear, an evaluation of TH disruption using more comprehensive in vivo models, e.g., zebrafish, is needed due to these models having a complete TH regulation system, such as hypothalamus-pituitary-thyroid (H-P-T) feedback. As a non-animal alternative model for chemical screening, zebrafish embryos can be used until the zebrafish starts to feed independently, which is at $5 \mathrm{~d}$ post fertilization (dpf) [17]. Despite morphological differences in its mature thyroid gland compared to higher vertebrates, the early steps in thyroid development of zebrafish show a significant resemblance [18,19]. From 70 to $80 \mathrm{~h}$ post fertilization (hpf), T4 synthesis in zebrafish embryo becomes detectable $[19,20]$.

The aim of this study was to evaluate the integrated TH-disrupting effects of BPAP, including phenotypic endpoints (development and behavior). Based on a previous review, an integrated approach that included a combination of morphological, behavioral, and molecular process assessments appears to be the most suitable for facilitating an understanding of the TH-disrupting effects [19]. In addition, we compared the TH-disrupting potency of BPAP with that of BPA and other alternatives to determine whether BPAP is relatively safe.

\section{Materials and Methods}

\subsection{Test Chemicals and Chemical Analysis}

BPAP (CAS RN. 1571-75-1) was purchased from Sigma Aldrich (St. Louis, MO, USA) (Table S1) and was dissolved in dimethyl sulfoxide (DMSO) at $0.1 \% v / v$. The exposure media were collected before and after the media were changed. It was vortexed weakly and separated by centrifuging for $5 \mathrm{~min}$ at $12,000 \mathrm{rpm}$. Then, the samples were filtered through $0.22 \mu \mathrm{m}$ filters for quantification.

The actual concentrations of BPAP in the exposure media were measured by high-performance liquid chromatography (HPLC; Agilent 1260 Infinity, Agilent Technologies, Palo Alto, CA, USA) coupled with an autosampler and diode array detector. The separation was performed using a Waters SunFire ${ }^{\mathrm{TM}} \mathrm{C} 18$ column $(100 \times 4.6 \mathrm{~mm}, 5 \mu \mathrm{m})$ with an isocratic mobile phase consisting of $30 \%$ water and $70 \%$ methanol. The flow rate was set to $1 \mathrm{~mL} / \mathrm{min}$. The autosampler and column oven temperatures 
were maintained at 4 and $50{ }^{\circ} \mathrm{C}$, respectively. The detection wavelength was set to $275 \mathrm{~nm}$, and the final injection volume of all the samples was $25 \mu \mathrm{L}$. The calibration curve for quantifying BPAP was linear, in the range of 10-3000 ng/mL, and the limit of quantification (LOQ) was determined as $\mathrm{LOQ}=10 \times(\mathrm{SD} / \mathrm{Slope})$, where SD is the standard deviation of the response, and slope is slope of the calibration curve. The measured concentrations are shown in Figure S1 and were used to present the results obtained in our study.

\subsection{Zebrafish Culture and Exposure Design}

Zebrafish (Danio rerio) embryos were obtained from mating pairs of wild-type adult zebrafish that were cultured under a constant temperature $\left(28 \pm 1^{\circ} \mathrm{C}\right)$ and a 14-h light/10-h dark photoperiod by the Biosystem Research Group at the Korea Institute of Toxicology (Daejeon, Korea). The embryos were collected and inspected under a stereomicroscope to select normally fertilized and developed embryos. The test solutions were prepared with $\mathrm{E} 3$ media, which contained $0.292 \mathrm{~g}$ of NaCl, $0.013 \mathrm{~g}$ of $\mathrm{KCl}, 0.044 \mathrm{~g}$ of $\mathrm{CaCl}_{2} \cdot 2 \mathrm{H}_{2} \mathrm{O}$, and $0.081 \mathrm{~g}$ of $\mathrm{MgSO}_{4} \cdot 7 \mathrm{H}_{2} \mathrm{O}$ in Millipore-filtered water $(1 \mathrm{~L})$. The exposure concentrations, i.e., solvent control (SC) and 18.2, 43.4, and 105.9 $\mu \mathrm{g} / \mathrm{L} \mathrm{BPAP}$, were determined as nonlethal concentrations based on the preliminary test (Figure S2). In our preliminary test, significant lethal effects were observed at $398.9 \mu \mathrm{g} / \mathrm{L}$ of BPAP but not at $105.9 \mu \mathrm{g} / \mathrm{L}$ of BPAP (>95\% survival rate was observed).

Embryos ( $\leq 3 \mathrm{hpf}$ ) were randomly distributed and exposed to the test chemical or the SC until $120 \mathrm{hpf}$, and the exposure medium was renewed every other day during the exposure period. For observations of hatching, growth, and malformation, the embryos were placed in 96-well plates. Triplicates of each treatment were prepared, and each replicate included eight larvae (one larva/well). To measure the TH level in zebrafish larvae, embryos (200 larvae per replicate, four replicates per treatment) were placed in a glass beaker (volume of $250 \mathrm{~mL}$ ). Another set of exposures using a glass beaker (volume of $50 \mathrm{~mL}$ ) was performed using triplicate samples (25 larvae per replicate) per treatment for transcription and transcriptome analysis, respectively. All exposure experiments were conducted in agreement with protocols approved by the Institutional Animal Care and Use Committee (IACUC) of the Korea Institute of Toxicology (Protocol No. KIT-1907-0263, approval date 29 July 2019). This experiment also complied with the ARRIVE guidelines [21] and was performed in accordance with the U.K. Animals (Scientific Procedures) Act of 1986 and associated guidelines, and the EU Directive 2010/63/EU for animal experiments [17].

\subsection{TH Measurement}

Following the exposure of embryos/larvae at $120 \mathrm{hpf}$, $\mathrm{TH}$ levels were measured from the homogenates of pooled fish ( $n=200$ /replicate) using an enzyme-linked immunosorbent assay (ELISA) according to the protocol described by Yu et al. (2010) [22] with minor modifications. Briefly, 200 zebrafish larvae in a glass beaker were homogenized in $200 \mu \mathrm{L}$ of $1 \times$ PBS using a pestle tissue grinder. The samples were then centrifuged for $10 \mathrm{~min}$ at $5000 \times g$ and $4{ }^{\circ} \mathrm{C}$. The supernatant of the samples was collected and stored at $-80^{\circ} \mathrm{C}$ until further measurement. The levels of hormones were quantified using ELISA kits (Cusabio Biotech, Wuhan, China) for T4 (Cat no. CSB-E08489f), T3 (Cat no. CSB-E08488f), and TSH $\beta$ (Cat no. CSB-EQ027261FI) with a BioTek Cytation 5 system (BioTek, Winooski, VT, USA) according to the manufacturer's recommended protocol. The optical density for T4, T3, and TSH $\beta$ was determined using BioTek Cytation 5 system (BioTek, Winooski, VT, USA) set to $450 \mathrm{~nm}$. The limits of detection for T4, T3, and TSH $\beta$ are reportedly $20 \mathrm{ng} / \mathrm{mL}, 0.5 \mathrm{ng} / \mathrm{mL}$, and $2.5 \mu \mathrm{IU} / \mathrm{mL}$, respectively. The measurements of $\mathrm{T} 4, \mathrm{~T} 3$, and $\mathrm{TSH} \beta$ were normalized to the protein level $(\mathrm{mg} / \mathrm{mL})$. Protein levels were analyzed using a BCA protein assay kit (Thermo Fisher Scientific, Johannesburg, South Africa) and BioTek citation 5 (BioTek, Winooski, VT, USA) system set to $562 \mathrm{~nm}$. 


\subsection{RNA Isolation and Quantitative RT-PCR}

For quantitative RT-PCR, 25 zebrafish larvae exposed to each replicate treatment were pooled and homogenized using a pestle tissue grinder. Total RNAs of the samples were then extracted using an RNeasy mini kit (Qiagen, Hilden, Germany). The total RNA concentration of each sample was detected using an ND-1000 spectrometer (NanoDrop Technologies, Wilmington, WD, USA). Reverse-transcribed complementary DNAs (cDNAs) were prepared using the iScript ${ }^{\mathrm{TM}}$ cDNA synthesis kit (BioRad, Hercules, CA, USA) and then, diluted to $300 \mathrm{ng} / \mu \mathrm{L}$. Quantitative real-time PCR (qRT-PCR) was performed using a StepOnePlus real-time PCR system (Applied Biosystems, Foster City, CA, USA) with a qRT-PCR mix (a total of $20 \mu \mathrm{L}$ ) that included an ABI SYBR Green Master Mix (10 $\mu \mathrm{L})$ (Applied Biosystems, Foster City, CA, USA), 10 pmol of the PCR primers (1.8 $\mu \mathrm{L}$ of each), purified PCR-grade water $(4.4 \mu \mathrm{L})$, and the cDNA sample $(2 \mu \mathrm{L})$. The thermal cycle profile was preincubation at $95^{\circ} \mathrm{C}$ for $10 \mathrm{~min}$ followed by 40 cycles of amplification at $95^{\circ} \mathrm{C}$ for $10 \mathrm{~s}, 60^{\circ} \mathrm{C}$ for $20 \mathrm{~s}$, and $72{ }^{\circ} \mathrm{C}$ for $20 \mathrm{~s}$. A melting curve analysis was performed to confirm the melting temperatures of the PCR products. The comparative $\mathrm{Ct}$ method $\left(2^{-\Delta \Delta \mathrm{Ct}}\right)$ was applied to calculate the relative transcription levels [23]. Sixteen genes related to thyroid stimulation ( $c r h$ and $t \operatorname{sh} \beta)$, thyroid development $(n k x 2.1$, hhex, tshr, slc5a5, tg, pax8, and tpo), TH receptors ( $\operatorname{tr} \alpha$ and $\operatorname{tr} \beta)$, TH transport (ttr), and TH metabolism (dio1, dio2, dio3, and ugt1ab) were selected. Due to its stable expression during the development of zebrafish, $18 \mathrm{~S}$ $r R N A$ was selected as the reference gene [24]. The primer sequences for the reference and target genes are shown in Table S2.

\subsection{RNA-Sequencing and Ingenuity Pathway Analysis (IPA)}

To elucidate the pathways underlying the induction of toxicity in response to BPAP exposure, an IPA was performed after RNA sequencing. The IPA results were obtained from a comparison between the SC group and the maximum nonlethal concentration group (105.9 $\mu \mathrm{g} / \mathrm{L} \mathrm{BPAP})$. RNA sequencing was conducted according to a previous study [25], and more detailed information is presented in the Supplementary Data. An integrated analysis of toxicity functions and canonical pathways was conducted using IPA software (IPA, Qiagen, Hilden, Germany) $(p<0.1)$ [26].

\subsection{Hatchability, Growth, and Morphological Observations}

The survival, hatching, and malformation of embryos/larvae were observed and recorded every $24 \mathrm{~h}$ during the exposure period. The incidences of mortality, hatching, and malformation were calculated in triplicate per concentration. After exposure, the body lengths and eyeball sizes of the zebrafish larvae were also measured $(n=5)$. For the measurement, the larvae were anesthetized by tricaine methane sulfonate $(0.004 \% w / v)$ and transferred to a glass slide containing methylcellulose. Then, individual images were taken using a Leica M205FA fluorescent microscope mounted with a Leica DFC 7000T camera module (Leica Camera AG, Wetzlar, Germany).

\subsection{Behavior Analysis (Locomotor Activity)}

Following BPAP exposure, the movement of zebrafish was monitored using an automated tracking device (DanioVision, Noldus Information Technology, Wageningen, The Netherlands). Four embryos/larvae were allocated to each replicate of each treatment group (SC and 18.2, 43.4, and $105.9 \mu \mathrm{g} / \mathrm{L} \mathrm{BPAP}, N=6$ ), and after $6 \mathrm{~min}$ of acclimation, the tracking was continued for four phases, which consisted of two cycles of a 6-min light/6-min dark period for a total of $24 \mathrm{~min}$. Using EthoVision software (Noldus Information Technology, Wageningen, The Netherlands), the distance moved $(\mathrm{cm})$ and moving duration $(\mathrm{s}$, time of moving speed $>0.2 \mathrm{~cm} / \mathrm{s})$ were calculated for each individual larvae [27]. 


\subsection{Statistical Analysis}

The normality of the distribution and the homogeneity of variance were analyzed using the Shapiro-Wilk test and Levene's test, respectively. To identify significant differences between the treatments and the SC, one-way analysis of variance (ANOVA) with Dunnett's and Dunnett's T3 post hoc analysis was performed using SPSS 12.0 for Windows ${ }^{\circledR}$ (SPSS, Chicago, IL, USA) for equal variances and unequal variances, respectively. The analysis of significant differences in nonparametric data was performed using the Kruskal-Wallis test. Differences with $p<0.05$ were considered statistically significant.

\subsection{Integrated Comparison with Other Bisphenols}

The results obtained in the present study were compared with those found for other bisphenols (BPA, BPF, BPS, and BPZ) in a previous study [3]. The maximum fold changes of multiple endpoints regarding TH disruption, e.g., gene transcription and hormonal levels, are presented using a star plot. A score of the integrated endpoints was calculated from the area of the star plot, i.e., the summation of multiple triangular areas consisting of two clockwise consecutive endpoints from the center [28].

\section{Results}

\subsection{Changes in the TH and TSH $\beta$ Levels}

In our study, BPAP decreased the T4 level in a dose-dependent manner, and only the maximum nonlethal concentration (105.9 $\mu \mathrm{g} / \mathrm{L} \mathrm{BPAP})$ induced a significant reduction (1.5-fold) (Figure 1a). However, significant effects on the T3 and TSH $\beta$ levels in the zebrafish larvae were not observed in the present study (Figure 1b,c).

(a)

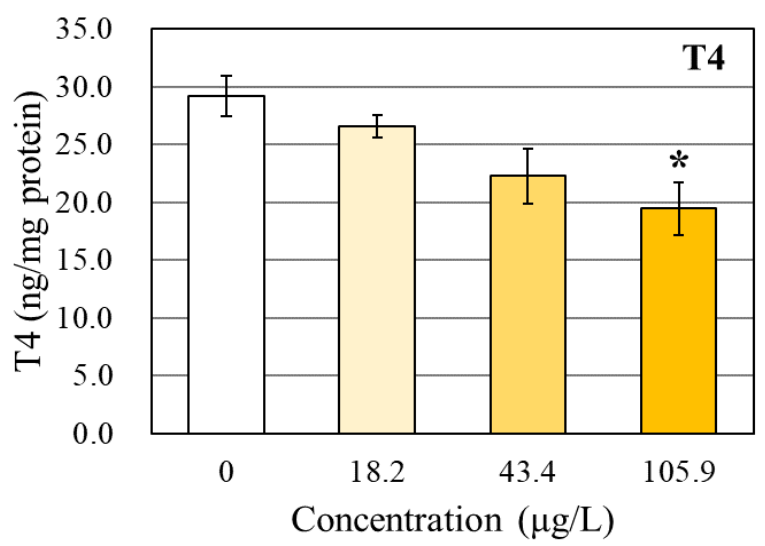

(b)

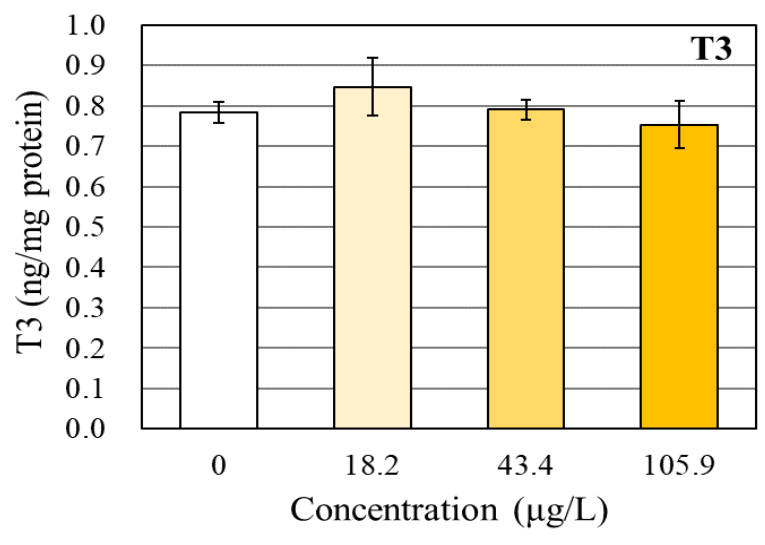

Figure 1. Cont. 
(c)

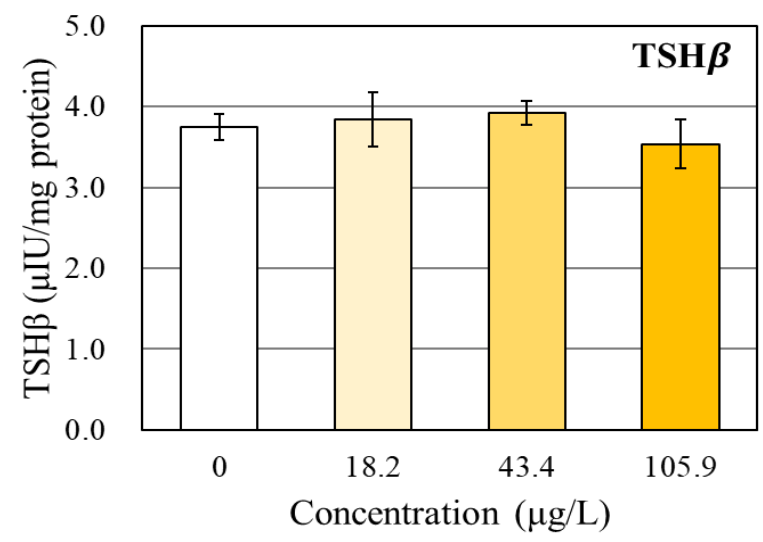

Figure 1. Hormonal levels in whole-body homogenates of zebrafish larvae after bisphenol AP (BPAP) exposure ((a) T4, (b) T3, and (c) TSH $\beta)$. The results are shown as the means \pm SEMs $(N=4)$. Asterisks $\left(^{*}\right)$ indicate significant differences compared with the solvent control $(0.1 \% v / v$ DMSO $)(p<0.05)$.

\subsection{Transcriptional Changes in TH-Related Genes}

BPAP exposure did not change the transcription of 16 genes related to the thyroid regulation system. Specifically, the transcription of genes involved in thyroid stimulation, i.e., $c r h$ and $t s h \beta$, was not significantly altered (Table 1). Among the genes related to TH synthesis, receptors, and transport, the transcription of the $t g$ and $t r \alpha$ genes in the zebrafish exposed to BPAP was more than 1.5-fold higher than that in the SC-treated zebrafish, but this difference was not statistically significant (Table 1). In addition, no significant changes in TH metabolism-related genes were detected (Table 1).

Table 1. TH-related gene transcription levels (fold changes) in whole-body homogenates of zebrafish larvae after BPAP exposure ((a) thyroid stimulation, (b) TH synthesis, (c) TH receptors and transport, and (d) TH metabolism).

\begin{tabular}{|c|c|c|c|c|c|c|c|}
\hline \multirow{2}{*}{$\begin{array}{l}\text { Conc. } \\
(\mu \mathrm{g} / \mathrm{L})\end{array}$} & \multicolumn{2}{|c|}{ Thyroid Stimulation } & \multicolumn{3}{|c|}{ TH Receptors and Transport } & & \\
\hline & crh & $t \operatorname{sh} \beta$ & $\operatorname{tr} \alpha$ & $\operatorname{tr} \beta$ & $t t r$ & & \\
\hline 0 & $1.00 \pm 0.21$ & $1.00 \pm 0.23$ & $1.00 \pm 0.34$ & $1.00 \pm 0.08$ & $1.00 \pm 0.08$ & & \\
\hline 18.2 & $0.72 \pm 0.18$ & $0.79 \pm 0.27$ & $1.43 \pm 0.37$ & $1.02 \pm 0.24$ & $1.00 \pm 0.15$ & & \\
\hline 43.4 & $0.89 \pm 0.16$ & $0.77 \pm 0.26$ & $1.83 \pm 0.31$ & $1.21 \pm 0.20$ & $1.15 \pm 0.26$ & & \\
\hline 105.9 & $1.13 \pm 0.10$ & $1.29 \pm 0.20$ & $1.57 \pm 0.28$ & $1.03 \pm 0.25$ & $1.16 \pm 0.22$ & & \\
\hline $\begin{array}{l}\text { Conc. } \\
(\mu \mathrm{g} / \mathrm{L})\end{array}$ & $n k x 2.1$ & hhex & $t s h r$ & $\begin{array}{l}\text { TH Synthesis } \\
\text { slc5a } 5\end{array}$ & $\operatorname{tg}^{a}$ & $\operatorname{Pax} 8$ & tpo \\
\hline 0 & $1.00 \pm 0.23$ & $1.00 \pm 0.15$ & $1.00 \pm 0.19$ & $1.00 \pm 0.17$ & $\begin{array}{c}1.02 \\
(0.92-1.07)\end{array}$ & $1.00 \pm 0.26$ & $1.00 \pm 0.08$ \\
\hline 18.2 & $0.79 \pm 0.25$ & $0.83 \pm 0.16$ & $0.72 \pm 0.25$ & $0.60 \pm 0.23$ & $\begin{array}{c}0.86 \\
(0.35-1.01)\end{array}$ & $0.72 \pm 0.10$ & $0.76 \pm 0.06$ \\
\hline 43.4 & $0.86 \pm 0.26$ & $0.94 \pm 0.13$ & $0.77 \pm 0.31$ & $0.55 \pm 0.23$ & $\begin{array}{c}1.03 \\
(0.93-2.25)\end{array}$ & $0.92 \pm 0.15$ & $0.98 \pm 0.07$ \\
\hline 105.9 & $1.26 \pm 0.26$ & $1.21 \pm 0.27$ & $1.19 \pm 0.27$ & $1.04 \pm 0.27$ & $\begin{array}{c}1.60 \\
(1.47-2.88)\end{array}$ & $0.78 \pm 0.19$ & $0.81 \pm 0.11$ \\
\hline
\end{tabular}


Table 1. Cont.

\begin{tabular}{|c|c|c|c|c|}
\hline \multirow{2}{*}{$\begin{array}{l}\text { Conc. } \\
(\mu \mathrm{g} / \mathrm{L})\end{array}$} & \multicolumn{4}{|c|}{ TH Metabolism } \\
\hline & dio1 & dio2 & $\operatorname{dio3}^{a}$ & $u g t 1 a b$ \\
\hline 0 & $1.00 \pm 0.19$ & $1.00 \pm 0.25$ & $\begin{array}{c}0.99 \\
(0.89-1.12)\end{array}$ & $1.00 \pm 0.17$ \\
\hline 18.2 & $0.97 \pm 0.03$ & $0.67 \pm 0.22$ & $\begin{array}{c}0.79 \\
(0.45-1.16)\end{array}$ & $0.75 \pm 0.10$ \\
\hline 43.4 & $1.11 \pm 0.13$ & $0.93 \pm 0.01$ & $\begin{array}{c}0.88 \\
(0.71-0.88)\end{array}$ & $0.91 \pm 0.08$ \\
\hline 105.9 & $1.11 \pm 0.03$ & $1.13 \pm 0.28$ & $\begin{array}{c}1.03 \\
(0.87-2.29)\end{array}$ & $1.17 \pm 0.19$ \\
\hline
\end{tabular}

The results are shown as the means \pm SEMs $(N=3)$. None of the effects were statistically significant compared with the solvent control $\left(0.1 \% v / v\right.$ DMSO) $(p<0.05){ }^{a}$ : Nonparametric data shown as the median with ranges.

\subsection{RNA Sequencing and IPA}

We found 32 toxicity functions with a $-\log (p$-value) over 1.0 from the IPA followed by RNA sequencing. Among these functions, the highly affected pathways were found to be related to renal function, cardiac function, and liver function (Figure 2). Toxicity functions directly linked to TH disruption were not found. Pathways linked to TH system regulation were also not observed among the canonical pathways derived from BPAP-exposed zebrafish larvae (Table S3).

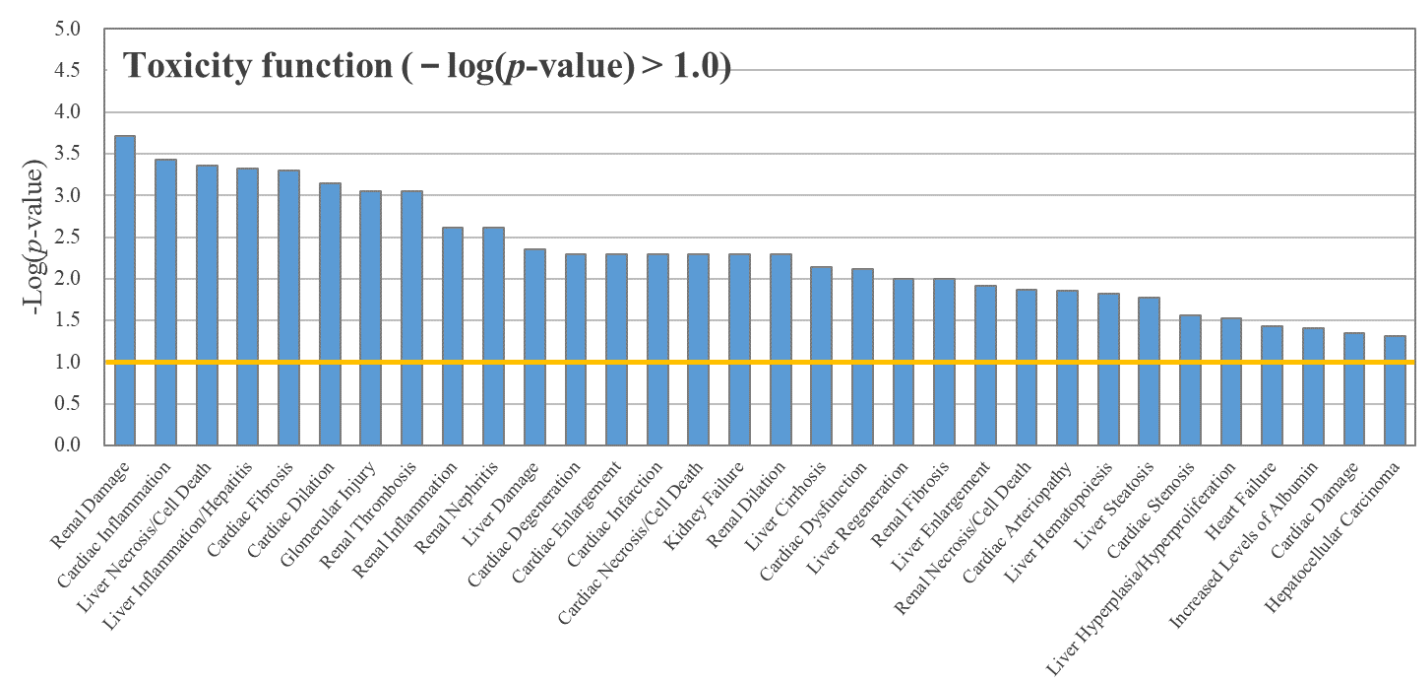

Figure 2. Toxicity functions in zebrafish larvae after BPAP exposure $(105.9 \mu \mathrm{g} / \mathrm{L})$. Toxicity functions with $-\log (p$-value) values higher than $1.0(N=3)$ were used in the ingenuity pathway analysis (IPA).

\subsection{Changes in Survival, Hatchability, Growth and Morphology}

Significant lethal effects were observed after exposure to $398.9 \mu \mathrm{g} / \mathrm{L}$ BPAP. Exposure to BPAP at levels up to $105.9 \mu \mathrm{g} / \mathrm{L}$ exerted no significant effects $(>95 \%)$ on the survival of zebrafish larvae (Figure S2). Thus, other observations (time to hatching, body length, eyeball size, morphology, and behavior) and analyses (TH analysis, gene transcription, and transcriptome) were performed after exposure to the SC and BPAP at concentrations up to $105.9 \mu \mathrm{g} / \mathrm{L}$.

All surviving embryos were successfully hatched (data not shown). The time to hatching was not significantly affected by exposure to BPAP at levels up to the maximum nonlethal concentration $(105.9 \mu \mathrm{g} / \mathrm{L})$ (Figure 3a). Additionally, BPAP did not exert any effects on malformation (Figure S3), body length, or eyeball size (Figure $3 b, c)$ ). 
(a)

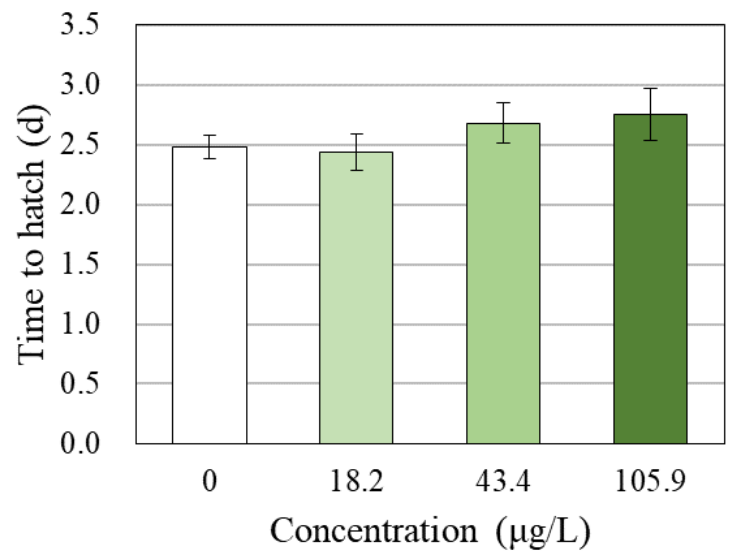

(b)

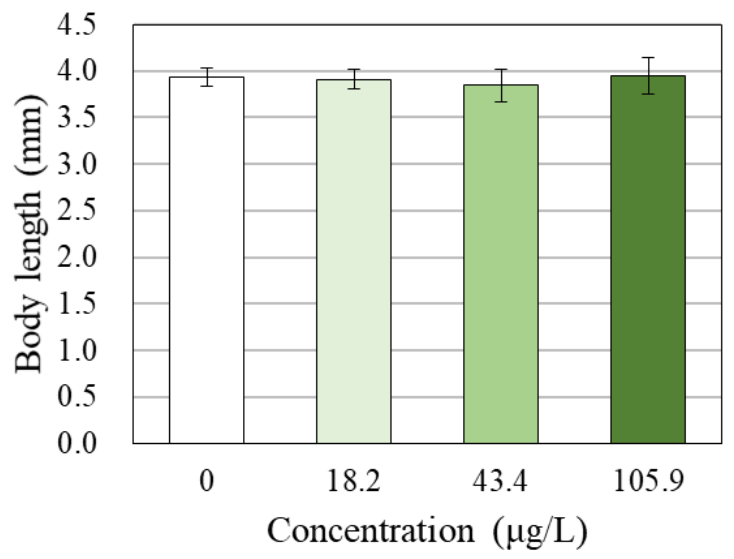

(c)

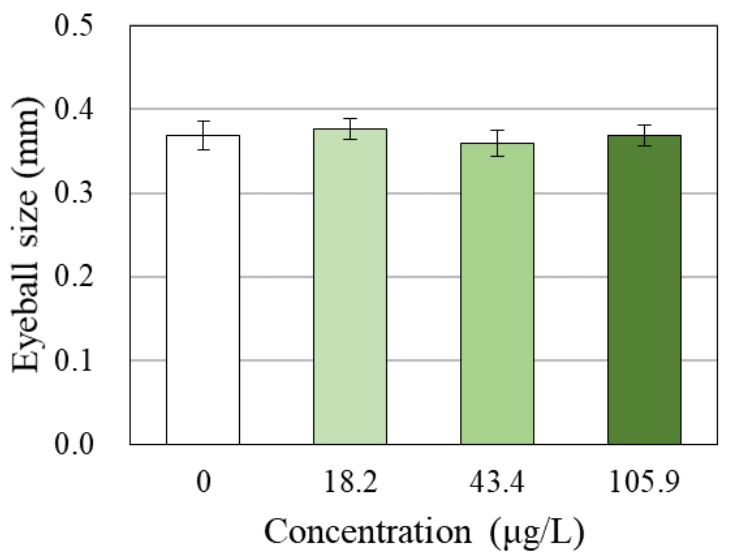

Figure 3. Effects of BPAP on (a) the time to hatch, (b) body length, and (c) eyeball size ( $N=3$ for time to hatch, $N=5$ for body length and eyeball size). The times to hatch, body lengths, and eyeball sizes are shown as the means \pm SDs. None of the effects were statistically significant compared with the solvent control $(0.1 \% v / v$ DMSO) $(p<0.05)$.

\subsection{Behavioral Changes}

The locomotor activity of zebrafish larvae exposed to BPAP did not differ from that of the SC group (Figure 4 and Figure S4). Exposure to BPAP to $120 \mathrm{~h}$ did not significantly alter the distance moved $(\mathrm{cm})$, although exposure to $105.9 \mu \mathrm{g} / \mathrm{L}$ BPAP decreased this distance in the dark phases by $14 \%$ compared with that obtained with the SC (Figure 4a). The moving duration (s, time of movement at a speed $>0.2 \mathrm{~cm} / \mathrm{s}$ ) was also not affected by BPAP exposure (Figure $4 \mathrm{~b}$ ). 
(a)

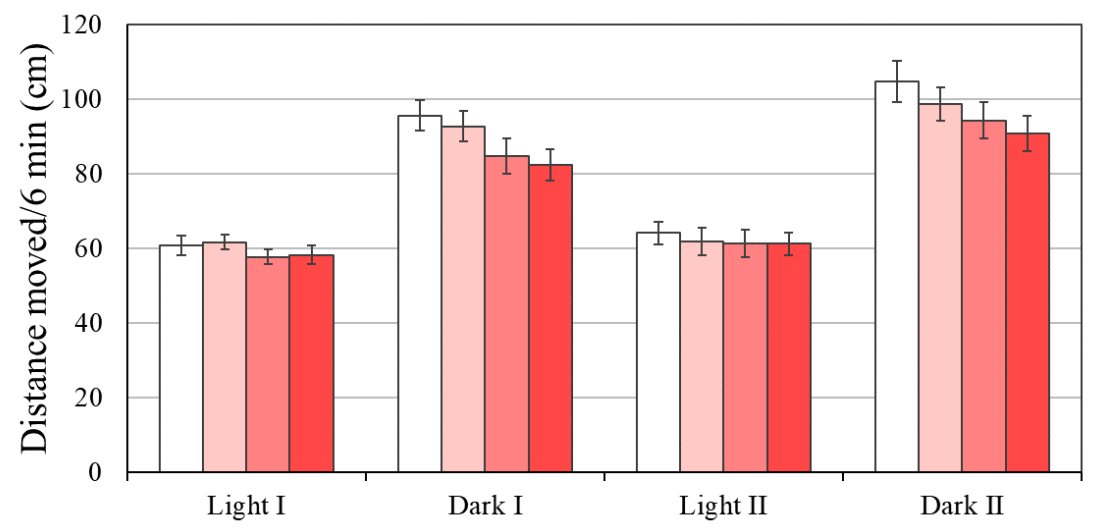

Concentration $(\mu \mathrm{g} / \mathrm{L}) \quad \square 0 \square 18.2 \square 43.4 \square 105.9$

(b)

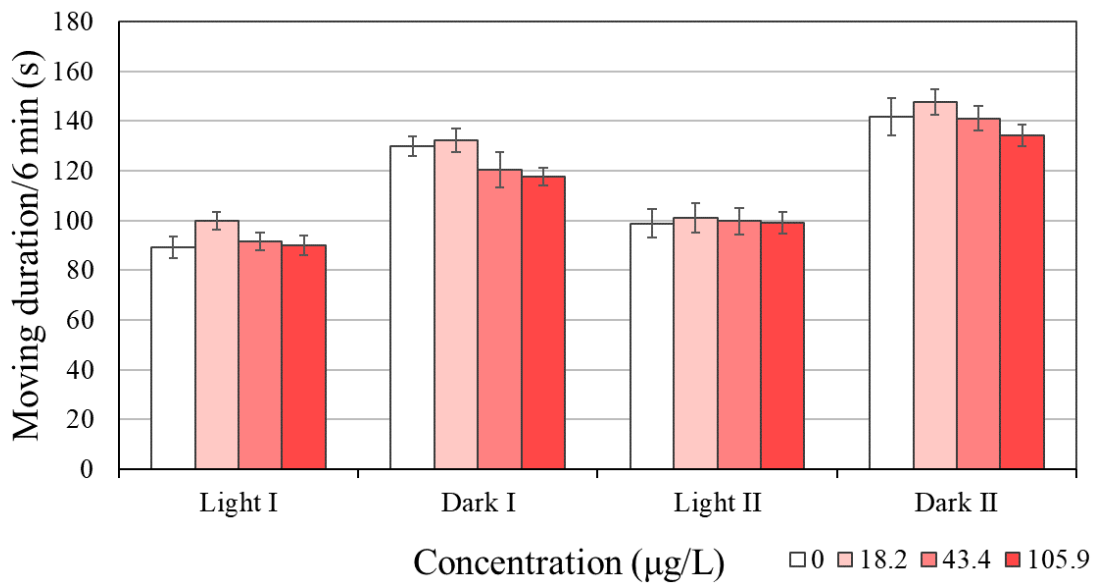

Figure 4. Locomotor activity ((a) distance moved and (b) moving duration) of zebrafish larvae after BPAP exposure. The moving duration was identified as the amount of time that the zebrafish moved at speeds over $0.2 \mathrm{~cm} / \mathrm{s}$. The results are shown as the means \pm SEMs $(N=6)$. None of the effects were statistically significant compared with the solvent control $(0.1 \% v / v$ DMSO $)(p<0.05)$.

\subsection{Integrated Comparison with Other Bisphenols}

The potency of the TH-disrupting effects of BPAP was relatively lower than that of the effects of other bisphenols (Figure 5), such as BPA, BPF, BPS, and BPZ [3]. The scores obtained from the integrated endpoints after BPS, BPF, BPA, BPZ, and BPAP exposure, i.e., the area of the star plot, were $11.5,8.9,7.3,7.0$, and 5.7, respectively. The comparison of these scores showed that none of the other bisphenols yielded a score lower than that obtained for BPAP. 


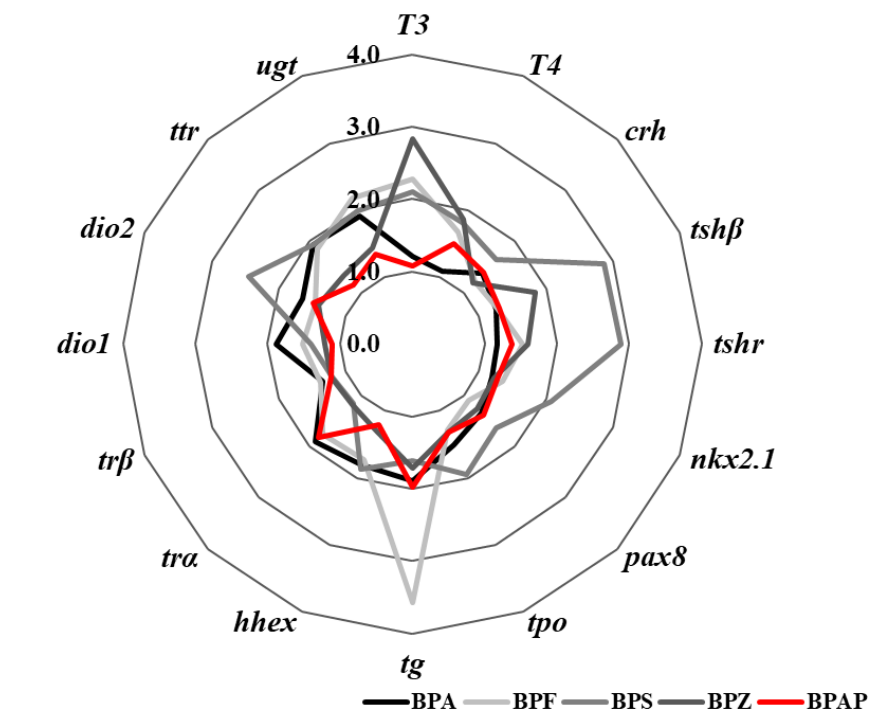

Score: $\operatorname{BPS}($ 11.5) $>\operatorname{BPF}($ 8.9) $>\operatorname{BPA}($ 7.3) $>\operatorname{BPZ}($ 7.0) $>\operatorname{BPAP}($ 5.7)

Figure 5. Comparison of the thyroid hormone-disrupting potential of BPAP with those of previously reported bisphenols, i.e., BPA, BPF, BPS, and BPZ (Lee et al., 2019).

\section{Discussion}

\subsection{Effects of BPAP on the TH Levels}

The physiological effects of BPAP on the TH system observed in our study were not substantial, although a significant reduction in T4 level (1.5-fold) was detected in zebrafish larvae exposed to the maximum concentration $(105.9 \mu \mathrm{g} / \mathrm{L})$ of BPAP. A change in the level of T4, which is the precursor of T3, can be regarded as a signal of TH disruption [29]. However, the physiological effects on the TH system should be assessed based on the T4, T3, and TSH $\beta$ levels rather than the T4 level alone [30]. In this study, the levels of TSH $\beta$ and T3 were not altered. T3, which is converted from T4 in peripheral tissue, is very important as the active form of $\mathrm{TH}[31]$. $\mathrm{TSH} \beta$, the major regulator of $\mathrm{TH}$ synthesis, is secreted from the pituitary and acts as a stimulation signal for TH synthesis in the thyroid gland [4]. Based on an analysis of the levels of T4, T3, and TSH $\beta$ together, the effects of BPAP on the TH regulation system are not clearly substantial.

Additionally, circumambient components around T4 did not support the TH-disrupting potential of BPAP. The reduction in T4 can be mainly attributed to a decrease in TH synthesis or an increase in the metabolism of T4 [1,32,33]. Based on our results, the transcription of genes related to thyroid stimulation and TH synthesis was not significantly changed (Table 1). As mentioned above, the hormonal level of TSH $\beta$ was also not decreased by BPAP (Figure 1c). The excess metabolism of the T4 hormone could be assessed by detecting the transcription of deiodinase (dio1, dio2, and dio3) and UDP-glucuronosyltransferase $(u g t 1 a b)$. The transcription of these genes was also not significantly affected (Table 1). Despite the reduction in the T4 level, the TH-disrupting potential of BPAP is not sufficiently clear.

\subsection{Effects of BPAP on Gene Transcription and the Transcriptome}

The effects of BPAP on TH disruption were not supported by the results from the analysis of gene transcription. In the zebrafish larvae exposed to BPAP, no significant changes in the transcription level of 16 genes related to thyroid stimulation and TH synthesis, receptors, transport, and metabolism were observed (Table 1). These genes were widely used as indicators of TH disruption in previous studies $[1,3,4]$. 
Among these genes, the transcription of the $t g$ and $t r$ genes was increased by more than 1.5 -fold by exposure to BPAP. As a precursor of TH, thyroglobulin, i.e., $t g$, has been proposed as a thyroid abnormality [34]. The direction of $t g$ transcription observed in our study might be interpreted as compensation for the reduction in T4 level because upregulation of the $t g$ gene could promote thyroid development to compensate for reductions in the T4 levels [4]. Previous studies showed that BPAP increased the transcription of the $t g$ gene and decreased the T4 level [1,31-33]. The direction of $t g$ gene transcription observed in our study was in accordance with that found in previous studies. However, our result did not reach statistical significance. TH receptors (TH receptor $\alpha(\operatorname{tr} \alpha)$ and $\mathrm{TH}$ receptor $\beta(\operatorname{tr} \beta))$ are members of the superfamily of ligand-dependent transcription factors [35]. When $\mathrm{T} 3$ binds to the $\mathrm{TH}$ receptor dimer, it activates gene transcription by releasing corepressors and recruiting coactivators [36]. In our study, $\operatorname{tr} \alpha$ transcription was upregulated by more than 1.5-fold after exposure to BPAP, but this difference was not statistically significant. Previous studies showed that decabromodiphenyl ether (BDE-209) and arsenite significantly increased the transcription of tr $\alpha$ and decreased the T4 level [34,37]. However, this finding might be due to an increase in T3, which was observed in response to decreases in the T4 level in both previous studies [34,37]. In the abovementioned previous studies, significant changes in deiodinase genes (dio1 and dio2) that convert $\mathrm{T} 4$ to T3 were also observed [34,37]. Another previous study also indicated that the administration of T3 induced the transcription of $\operatorname{tr} \alpha$ and $\operatorname{tr} \beta$ [38]. In our study, BPAP did not affect the T3 level in zebrafish larvae.

The transcriptome analysis does not support the disruption of TH by BPAP. Specifically, BPAP did not induce changes in transcriptome-related TH disruption. RNA sequencing and IPA provide the ability to map differentially expressed proteins to fixed canonical pathways [26]. In addition, an analysis of toxicity functions by IPA reveals biological mechanisms that are related to toxicity [26]. We conducted RNA sequencing and IPA to observe the changes in the whole transcriptome between the SC group and the $105.9 \mu \mathrm{g} / \mathrm{L}$ BPAP exposure group. Pathways directly related to the TH system were not found among the obtained lists of toxicity functions and canonical pathways ( $p$-value $<0.1$ ) (Figure 2 and Table S3). The major toxicity functions identified to be associated with BPAP exposure were mainly related to renal, heart, and liver damage, cardiac inflammation, or liver necrosis/cell death. Surely, THs are involved in various physiological functions. For example, hypothyroidism is accompanied by a decrease in glomerular filtration, hyponatremia, and alteration of water excretion ability [39,40]. Additionally, THs are known to modulate the components of the cardiovascular system necessary for normal cardiovascular development and function [41]. The disruption of cellular TH signaling triggers chronic liver diseases and nonalcoholic fatty liver disease [42,43]. However, because toxicity functions and canonical pathways related to the TH system were not identified from the transcriptome changes, the transcriptome changes induced by BPAP exposure were not unlikely changed by TH disruption. The overall gene transcription and RNA sequencing results obtained in our study might imply that the thyroid disruption obtained with BPAP is not sufficiently strong to induce the following toxicity functions.

\subsection{Effects of BPAP on Hatching, Growth and Behavior}

Even at the phenotypic level, the TH-disrupting effects of BPAP were not confirmed in our study. Phenotypic endpoints were suggested as one of the components in the integrated approach for the suitable assessment of TH disruption [19]. A previous study suggested hatching, body length, eye impairment, morphological effects, and behavioral effects as indicators that should be monitored with the endpoints of $\mathrm{TH}$ disruption and demonstrated that these indicators show responses of $82 \%$, $58 \%, 42 \%, 87 \%$, and $69 \%$, respectively, to substances that cause TH disruption [19]). Bisphenol F, S, and $\mathrm{Z}$, which have been used as BPA analogs similar to BPAP, also induced changes in the time to hatch or a reduced eyeball size ratio accompanied by a significant TH increase [3]. In the present study, however, zebrafish exposed to BPAP did not exhibit significant changes in hatching, body length, eyeball size, or morphological abnormalities (Figure 3 and Figure S3). 
Behavior might also be affected by TH-disrupting substances, and the assumption that TH disruption is associated with neurotoxicity was previously proposed [44]. In addition, behavioral assessment has been used as an observation point more frequently in thyroid-related studies than in other type of studies [19]. In our study, BPAP failed to result in significant changes in the locomotor activity (distance moved) of zebrafish (Figure 4a). Consistent with the typical nature of zebrafish, increased movement in the dark phase compared with the light phase was found in the present study (Figure 4a). In addition, BPAP exposure did not affect the moving duration, which indicates that the zebrafish moved faster than $0.2 \mathrm{~cm} / \mathrm{s}$ (Figure $4 \mathrm{~b}$ ). Based on the overall phenotypic indicators, i.e., hatching, body length, eye impairment, morphological effects, and behavioral effects, our results might indicate that the TH-disrupting effects of BPAP are negligible.

\subsection{Disruption Potency of BPAP in Comparison with that of Other Bisphenols}

The TH-disrupting effects of BPAP appeared to be relatively lower than those of other bisphenols (Figure 5). Although the weight of individual markers used to determine the score of integrated endpoints might not be equal, we believe that the relative comparison of integrated molecular levels might provide insight into TH disruption-safer chemicals, and our results might indicate that BPAP is relatively safer than other bisphenols with respect to TH disruption. Based on previous studies, even the estrogen receptor $\alpha$ binding and genotoxic potencies of BPAP were lower than those of BPA, although further in-depth study is needed $[45,46]$.

\section{Conclusions}

Despite the observed reduction in the T4 level, other markers for gene transcription, transcriptome, development, and behavior were not significantly affected in zebrafish exposed to BPAP at levels up to sublethal concentrations. Thus, our results might indicate that BPAP exhibits negligible or weak potency for TH disruption. In addition, BPAP exerted a relatively lower impact on TH disruption than other bisphenols, i.e., BPA, BPF, BPS, and BPZ. Thus, based on its TH-disrupting effects, BPAP could be considered a safer alternative chemical to BPA. This study can provide novel information about the potential thyroid-disrupting effects of BPAP and might help society develop and select safer substitutes.

Supplementary Materials: The following are available online at http://www.mdpi.com/2305-6304/8/4/103/s1, Figure S1: Measured concentrations of BPAP, Figure S2: Survival of zebrafish embryos/larvae after $120 \mathrm{~h}$ of exposure to BPAP, Figure S3: Morphology of zebrafish larvae after $120 \mathrm{~h}$ of exposure to (a) the solvent control $(0.1 \%$ v/v DMSO) and (b) $18.2 \mu \mathrm{g} / \mathrm{L}$, (c) $43.4 \mu \mathrm{g} / \mathrm{L}$ and (d) $105.9 \mu \mathrm{g} / \mathrm{L} \mathrm{BPAP,} \mathrm{Figure} \mathrm{S4:} \mathrm{Locomotor} \mathrm{activity} \mathrm{((a)}$ distance moved and (b) moving duration)) per minute obtained for the zebrafish larvae after BPAP exposure $(N=6)$, Table S1: Molecular structure and characteristics of BPAP, Table S2: Primer sequences used in the qRT-PCR analysis in the present study, Table S3: Ingenuity canonical pathways determined by IPA.

Author Contributions: Conceptualization, S.L. and W.-K.K.; methodology, S.L.; software, K.E.; validation, K.E. and D.Y.; formal analysis, K.E. and J.L.; investigation, S.L. and K.E.; resources, S.Y. and W.-K.K.; data curation, S.L. and K.E.; writing-original draft preparation, S.L.; writing-review and editing, W.-K.K.; visualization, S.L.; supervision, S.Y. and W.-K.K.; project administration, S.L.; funding acquisition, S.L. All authors have read and agreed to the published version of the manuscript.

Funding: This research was funded by National Research Foundation of Korea, grant number 2017R1D1A1B03032141 and 2020R1F1A074971 and by Korea Environmental Industry and Technology Institute, grant number 2019002490006.

Conflicts of Interest: The authors declare no conflict of interest. The funders had no role in the design of the study; in the collection, analyses, or interpretation of data; in the writing of the manuscript, or in the decision to publish the results. 


\section{References}

1. Zhang, D.H.; Zhou, E.X.; Yang, Z.L. Waterborne exposure to BPS causes thyroid endocrine disruption in zebrafish larvae. PLoS ONE 2017, 12, e0176927. [CrossRef] [PubMed]

2. Zhang, Y.F.; Ren, X.M.; Li, Y.Y.; Yao, X.F.; Li, C.H.; Qin, Z.F.; Guo, L.H. Bisphenol A alternatives bisphenol $\mathrm{S}$ and bisphenol $\mathrm{F}$ interfere with thyroid hormone signaling pathway in vitro and in vivo. Environ. Pollut. 2018, 237, 1072-1079. [CrossRef] [PubMed]

3. Lee, S.; Kim, C.; Shin, H.; Kho, Y.; Choi, K. Comparison of thyroid hormone disruption potentials by bisphenols A, S, F, and Z in embryo-larval zebrafish. Chemosphere 2019, 221, 115-123. [CrossRef] [PubMed]

4. Huang, G.M.; Tian, X.F.; Fang, X.D.; Ji, F.J. Waterborne exposure to bisphenol F causes thyroid endocrine disruption in zebrafish larvae. Chemosphere 2016, 147, 188-194. [CrossRef] [PubMed]

5. Tang, T.; Yang, Y.; Chen, Y.; Tang, W.; Wang, F.; Diao, X. Thyroid Disruption in Zebrafish Larvae by Short-Term Exposure to Bisphenol AF. Int. J. Environ. Res. Public Health 2015, 12, 13069-13084. [CrossRef]

6. Zhang, L.; Fang, P.; Yang, L.; Zhang, J.; Wang, X. Rapid method for the separation and recovery of endocrine-disrupting compound bisphenol AP from wastewater. Langmuir 2013, 29, 3968-3975. [CrossRef]

7. Xiao, X.; Li, J.; Yu, T.; Zhou, L.; Fan, X.; Xiao, H.; Wang, Y.; Yang, L.; Lv, J.; Jia, X.; et al. Bisphenol AP is anti-estrogenic and may cause adverse effects at low doses relevant to human exposure. Environ. Pollut. 2018, 242, 1625-1632. [CrossRef]

8. Liao, C.; Kannan, K. A survey of alkylphenols, bisphenols, and triclosan in personal care products from China and the United States. Arch. Environ. Contam. Toxicol. 2014, 67, 50-59. [CrossRef]

9. Liao, C.; Kannan, K. A survey of bisphenol A and other bisphenol analogues in foodstuffs from nine cities in China. Food Addit. Contam. Part A Chem. Anal. Control Expo Risk Assess. 2014, 31, 319-329. [CrossRef]

10. Asimakopoulos, A.G.; Xue, J.; De Carvalho, B.P.; Iyer, A.; Abualnaja, K.O.; Yaghmoor, S.S.; Kumosani, T.A.; Kannan, K. Urinary biomarkers of exposure to 57 xenobiotics and its association with oxidative stress in a population in Jeddah, Saudi Arabia. Environ. Res. 2016, 150, 573-581. [CrossRef]

11. Zhang, T.; Xue, J.; Gao, C.Z.; Qiu, R.L.; Li, Y.X.; Li, X.; Huang, M.Z.; Kannan, K. Urinary Concentrations of bisphenols and their association with biomarkers of oxidative stress in people living near E-waste recycling facilities in China. Environ. Sci. Technol. 2016, 50, 4045-4053. [CrossRef] [PubMed]

12. Chen, Y.; Fang, J.; Ren, L.; Fan, R.; Zhang, J.; Liu, G.; Zhou, L.; Chen, D.; Yu, Y.; Lu, S. Urinary bisphenol analogues and triclosan in children from south China and implications for human exposure. Environ. Pollut. 2018, 238, 299-305. [CrossRef] [PubMed]

13. Yan, Z.; Liu, Q.; Yan, K.; Wu, S.; Han, Z.; Guo, R.; Chen, M.; Yang, Q.; Zhang, S.; Chen, J. Bisphenol analogues in surface water and sediment from the shallow Chinese freshwater lakes: Occurrence, distribution, source apportionment, and ecological and human health risk. Chemosphere 2017, 184, 318-328. [CrossRef] [PubMed]

14. Lee, S.; Liao, C.; Song, G.J.; Ra, K.; Kannan, K.; Moon, H.B. Emission of bisphenol analogues including bisphenol A and bisphenol F from wastewater treatment plants in Korea. Chemosphere 2015, 119, 1000-1006. [CrossRef]

15. Lee, S.; Kim, C.; Youn, H.; Choi, K. Thyroid hormone disrupting potentials of bisphenol A and its analogues-In vitro comparison study employing rat pituitary (GH3) and thyroid follicular (FRTL-5) cells. Toxicol. In Vitro 2017, 40, 297-304. [CrossRef]

16. Lee, J.; Kim, S.; Choi, K.; Ji, K. Effects of bisphenol analogs on thyroid endocrine system and possible interaction with 17beta-estradiol using GH3 cells. Toxicol. In Vitro 2018, 53, 107-113. [CrossRef]

17. European Parliament and the Council of the European Union. Directive 2010/63/EU of the European Parliament and of the Council of 22 September 2010 on the Protection of Animals Used for Scientific Purposes. Off. J. Eur. Union 2010, 53, 33-79.

18. Elsalini, O.S.; Gartzen, J.; Cramer, M.; Rohr, K.B. Zebrafish hhex, nk2.1a, and pax2.1 regulate thyroid growth and differentiation downstream of Nodel-dependent transcription factors. Dev. Biol. 2003, 263, 67-80. [CrossRef]

19. Spaan, K.; Haigis, A.C.; Weiss, J.; Legradi, J. Effects of 25 thyroid hormone disruptors on zebrafish embryos: A literature review of potential biomarkers. Sci. Total Environ. 2019, 656, 1238-1249. [CrossRef]

20. Optiz, R.; Antonica, F.; Costagliola, S. New model system to illuminate thyroid organogenesis. Part I: An update on the zebrafish toolbox. Eur. Thyroid J. 2013, 2, 229-242. [CrossRef] 
21. Percie du Sert, N.; Ahluwalia, A.; Alam, S.; Avey, M.T.; Baker, M.; Browne, W.J.; Clark, A.; Cuthill, I.C.; Dirnagl, U.; Emerson, M.; et al. Reporting animal research: Explanation and elaboration for the ARRIVE guidelines 2.0. PLoS Biol. 2020, 18, e3000411. [CrossRef]

22. Yu, L.; Deng, J.; Shi, X.; Liu, C.; Yu, K.; Zhou, B. Exposure to DE-71 alters thyroid hormone levels and gene transcription in the hypothalamic-pituitary-thyroid axis of zebrafish larvae. Aquat. Toxicol. 2010, 97, 226-233. [CrossRef] [PubMed]

23. Livak, K.J.; Schmittgen, T.D. Analysis of relative gene expression data using real-time quantitative PCR and the 2(-Delta Delta C(T)) Method. Methods 2001, 25, 402-408. [CrossRef] [PubMed]

24. McCurley, A.T.; Callard, G.V. Characterization of housekeeping genes in zebrafish: Male-female differences and effects of tissue type, developmental stage and chemical treatment. BMC Mol. Biol. 2008, 9, 102. [CrossRef] [PubMed]

25. Lee, S.; Chun, H.S.; Lee, J.; Park, H.J.; Kim, K.T.; Kim, C.H.; Yoon, S.; Kim, W.K. Plausibility of the zebrafish embryos/larvae as an alternative animal model for autism: A comparison study of transcriptome changes. PLoS ONE 2018, 13, e0203543. [CrossRef]

26. Dong, X.; Qiu, X.; Meng, S.; Xu, H.; Wu, X.; Yang, M. Proteomic profile and toxicity pathway analysis in zebrafish embryos exposed to bisphenol A and di-n-butyl phthalate at environmentally relevant levels. Chemosphere 2018, 193, 313-320. [CrossRef]

27. Steele, W.B.; Mole, R.A.; Brooks, B.W. Experimental Protocol for Examining Behavioral Response Profiles in Larval Fish: Application to the Neuro-stimulant Caffeine. JoVE J. Vis. Exp. 2018, e57938. [CrossRef]

28. Kim, W.K.; Lee, S.K.; Choi, K.; Jung, J. Integrative assessment of biomarker responses in pale chub (Zacco platypus) exposed to copper and benzo[a]pyrene. Ecotoxicol. Environ. Saf. 2013, 92, 71-78. [CrossRef]

29. Yu, L.Q.; Zhao, G.F.; Feng, M.; Wen, W.; Li, K.; Zhang, P.W.; Peng, X.; Huo, W.J.; Zhou, H.D. Chronic exposure to pentachlorophenol alters thyroid hormones and thyroid hormone pathway mRNAs in zebrafish. Environ. Toxicol. Chem. 2014, 33, 170-176. [CrossRef]

30. Boas, M.; Feldt-Rasmussen, U.; Main, K.M. Thyroid effects of endocrine disrupting chemicals. Mol. Cell. Endocrinol. 2012, 355, 240-248. [CrossRef]

31. Chen, R.; Yuan, L.; Zha, J.; Wang, Z. Developmental toxicity and thyroid hormone-disrupting effects of 2,4-dichloro-6-nitrophenol in Chinese rare minnow (Gobiocypris rarus). Aquat. Toxicol. 2017, 185, 40-47. [CrossRef] [PubMed]

32. Guo, Y.; Zhou, B. Thyroid endocrine system disruption by pentachlorophenol: An in vitro and in vivo assay. Aquat. Toxicol. 2013, 142-143, 138-145. [CrossRef] [PubMed]

33. Wang, Q.; Liang, K.; Liu, J.; Yang, L.; Guo, Y.; Liu, C.; Zhou, B. Exposure of zebrafish embryos/larvae to TDCPP alters concentrations of thyroid hormones and transcriptions of genes involved in the hypothalamic-pituitary-thyroid axis. Aquat. Toxicol. 2013, 126, 207-213. [CrossRef] [PubMed]

34. Sun, H.J.; Li, H.B.; Xiang, P.; Zhang, X.; Ma, L.Q. Short-term exposure of arsenite disrupted thyroid endocrine system and altered gene transcription in the HPT axis in zebrafish. Environ. Pollut. 2015, 205, 145-152. [CrossRef] [PubMed]

35. Zoeller, R.T.; Tan, S.W.; Tyl, R.W. General background on the hypothalamic-pituitary-thyroid (HPT) axis. Crit. Rev. Toxicol. 2007, 37, 11-53. [CrossRef] [PubMed]

36. Ortiga-Carvalho, T.M.; Sidhaye, A.R.; Wondisford, F.E. Thyroid hormone receptors and resistance to thyroid hormone disorders. Nat. Rev. Endocrinol. 2014, 10, 582-591. [CrossRef]

37. Chen, Q.; Yu, L.; Yang, L.; Zhou, B. Bioconcentration and metabolism of decabromodiphenyl ether (BDE-209) result in thyroid endocrine disruption in zebrafish larvae. Aquat. Toxicol. 2012, 110-111, 141-148. [CrossRef]

38. Crump, D.; Jagla, M.M.; Kehoe, A.; Kennedy, S.W. Detection of Polybrominated Diphenyl Ethers in Herring Gull (Larus argentatus) brains: Effects on mRNA Expression in Cultured Neuronal Cells. Environ. Sci. Technol. 2008, 42, 7715-7721. [CrossRef]

39. Iglesias, P.; Diez, J.J. Thyroid dysfunction and kidney disease. Eur. J. Endocrinol. 2009, 160, 503-515. [CrossRef]

40. Schairer, B.; Jungreithmayr, V.; Schuster, M.; Reiter, T.; Herkner, H.; Gessl, A.; Sengolge, G.; Winnicki, W. Effect of Thyroid Hormones on Kidney Function in Patients after Kidney Transplantation. Sci. Rep. 2020, 10, 2156. [CrossRef] 
41. Grais, I.M.; Sowers, J.R. Thyroid and the Heart. Am. J. Med. 2014, 127, 691-698. [CrossRef] [PubMed]

42. Chi, H.C.; Chen, C.Y.; Tsai, M.M.; Tsai, C.Y.; Lin, K.H. Molecular functions of thyroid hormones and their clinical significance in liver-related diseases. BioMed Res. Int. 2013, 2013, 601361. [CrossRef] [PubMed]

43. Sinha, R.A.; Singh, B.K.; Yen, P.M. Direct effects of thyroid hormones on hepatic lipid metabolism. Nat. Rev. Endocrinol. 2018, 14, 259-269. [CrossRef] [PubMed]

44. Chou, C.-T.; Hsiao, Y.-C.; Ko, F.-C.; Cheng, J.-O.; Cheng, Y.-M.; Chen, T.-H. Chronic exposure of 2,2',4,4'-tetrabromodiphenyl ether (PBDE-47) alters locomotion behavior in juvenile zebrafish (Danio rerio). Aquat. Toxicol. 2010, 98, 388-395. [CrossRef] [PubMed]

45. Lee, S.; Liu, X.; Takeda, S.; Choi, K. Genotoxic potentials and related mechanisms of bisphenol A and other bisphenol compounds: A comparison study employing chicken DT40 cells. Chemosphere 2013, 93, 434-440. [CrossRef]

46. Mesnage, R.; Phedonos, A.; Arno, M.; Balu, S.; Corton, J.C.; Antoniou, M.N. Transcriptome Profiling Reveals Bisphenol A Alternatives Activate Estrogen Receptor Alpha in Human Breast Cancer Cells. Toxicol. Sci. 2017, 158, 431-443. [CrossRef]

Publisher's Note: MDPI stays neutral with regard to jurisdictional claims in published maps and institutional affiliations.

(C) 2020 by the authors. Licensee MDPI, Basel, Switzerland. This article is an open access article distributed under the terms and conditions of the Creative Commons Attribution (CC BY) license (http://creativecommons.org/licenses/by/4.0/). 